\title{
REGULAÇÃO E TRANSPARÊNCIA: EVIDÊNCIAS A PARTIR DA CRISE DO SUBPRIME*
}

\author{
Helder Ferreira de Mendonça ${ }^{\dagger}$ \\ Délio José Cordeiro Galvão ‡ \\ Renato Falci Villela Loures $\S$
}

\begin{abstract}
Resumo
Este artigo destaca o momento em que ocorreu o choque de liquidez no período pós-crise do subprime nos EUA e tem como principais objetivos: (i) construir um indicador de transparência informacional, tanto levando em consideração os aspectos de exigência regulatória quanto os de self-disclosure; e (ii) relacionar este indicador com o desempenho do mercado acionário. Neste estudo são consideradas grandes instituições financeiras com sedes em 25 países divididos em quatro grupos de países: desenvolvidos, em desenvolvimento, BRIC, e PIGS. Os resultados indicam que a redução na flexibilidade das regras de supervisão pode levar a uma menor vulnerabilidade dos mercados financeiros. Em suma, os resultados encontrados reforçam a ideia de que a regulação do sistema financeiro não é neutra em termos macroeconômicos.
\end{abstract}

\begin{abstract}
This article highlights the moment when the liquidity shock occurred in the period after the subprime crisis in the USA and has as the main objectives: (i) to build an index of informational transparency, taking into consideration both aspects of regulation and of self-disclosure; and (ii) to make a relation of this index with the stock market performance. This study considers large financial institutions from 25 countries divided in four groups of countries: developed, developing, BRIC, and PIGS. The findings denote that reducing the flexibility in the rules of supervision can lead to lesser vulnerability of the financial markets. In brief, the results found strengthen the idea that the regulation of the financial system is not neutral in macroeconomic terms.
\end{abstract}

Keywords: Regulation, Transparency, Banks, Subprime Crisis

JEL classification: G15, G18, G14

\footnotetext{
* Agradecemos aos profícuos comentários realizados por dois pareceristas anônimos. Como de praxe, as possíveis omissões ou imprecisões são de inteira responsabilidade dos autores. As opiniões expressas neste trabalho são exclusivamente dos autores e não refletem a visão do Banco Central do Brasil.

† Universidade Federal Fluminense e CNPq. E-mail: helderfm@hotmail.com.

$\ddagger$ Banco Central do Brasil e Universidade Federal Fluminense.

E-mail: delio.galvao@yahoo.com.br.

$\S$ Universidade Federal Fluminense e CAPES. E-mail: rfvloures@gmail.com.
} 


\section{Introdução}

Uma das inovações do Acordo de Basiléia II foi a maior liberdade dada às instituições financeiras para escolha do método de cálculo dos riscos a que estão dispostas a incorrer. Contudo, a crise internacional deflagrada a partir do segundo semestre de 2008 levanta dúvidas quanto às atuais regras de regulação do sistema bancário e revela a necessidade de se buscar meios capazes de reduzir a probabilidade de ocorrência de novas crises. Diante de uma maior demanda da sociedade pelo aprimoramento das regras de regulação, emerge a dúvida de que os bancos sejam, efetivamente, os melhores gestores para avaliação de riscos.

Ao analisar a crise do subprime, em recente estudo divulgado pelo FMI, Blanchard et al. (2010) defendem que os bancos centrais devem perseguir outros objetivos que não só o de uma inflação baixa capaz de criar um ambiente propício ao crescimento econômico. Outrossim, devem buscar a estabilidade financeira e o combate a formação de novas bolhas de ativos. Neste sentido, segundo os autores, os bancos centrais precisam fazer uso não só das tradicionais ferramentas de política monetária, como os ajustes na taxa de juros, mas também de políticas regulatórias.

Estudos sobre regulação e transparência nos bancos centrais têm se tornado frequentes na literatura contemporânea. Segundo de Mendonça e Simão Filho (2008) a transparência na condução da política monetária pode ser justificada pela existência de assimetrias de informação entre a autoridade monetária e outros agentes econômicos. Um elevado grau de transparência reduz as incertezas, desenvolve a capacidade do setor privado em inferir sobre as decisões do banco central e aumenta a eficiência da política monetária. Contudo, a falta de transparência de informações entre os agentes do mercado financeiro mostrou-se um importante elemento na causa e disseminação da crise do subprime. Ademais, têm-se colocado em dúvida as vantagens da tendência à auto-regulação do mercado financeiro e de capitais, iniciada no final década de 1980, e defendida, por exemplo, por Alan Greespan (ex-presidente do Fed).

Não obstante, é importante destacar que há o risco de se criar uma regulação excessiva e ineficaz do mercado financeiro. Por exemplo, durante a crise do subprime os setores envolvidos no epicentro da crise eram os mais regulados (bancos, seguros, e financiamento imobiliário). Logo, qualquer modificação na atual regulação deveria buscar simplicidade e eficiência. Trata-se, em verdade, de uma linha tênue que separa o engessamento do mercado financeiro, que uma regulação excessiva poderia causar, e a real necessidade de aumento de liquidez e crédito, essenciais ao crescimento econômico.

Este artigo destaca o momento em que ocorreu o choque de liquidez no período pós-crise do subprime nos EUA e tem como principais objetivos: (i) construir um indicador de transparência informacional, tanto levando em consideração os aspectos de exigência regulatória quanto os de self-disclosure; e (ii) relacionar este indicador com o desempenho do mercado acionário. Neste estudo são consideradas grandes instituições financeiras com sedes em 25 países levando em conta quatro grupos de países: desenvolvidos, em desenvolvimento, BRIC, e PIGS.

Além desta introdução, o artigo possui mais quatro seções. A segunda seção apresenta as principais características do Novo Acordo de Basiléia referentes à regulação bancária e também os principais fatos associados com a 
crise do subprime. A seção 3 elabora o índice de transparência e regulação das instituições financeiras e realiza uma análise do seu desempenho no caso de: países desenvolvidos, em desenvolvimento, BRIC, e os PIGS. A seção 4 apresenta evidências empíricas por meio do uso de estimações cross-country(OLS) para verificar o efeito deste indicador sobre a volatilidade e retorno dos índices das bolsas de valores dos países considerados no estudo. Por último são apresentadas as conclusões do trabalho.

\section{Antecedentes da crise do subprime}

O início do processo de regulação prudencial do sistema financeiro pode ser atribuído às medidas adotadas nos EUA, em decorrência da corrida bancária observada depois da quebra da bolsa de Nova York, em outubro de 1929. Em 1933, o congresso norte americano aprovou a segunda Lei Glass Steagall $(\mathrm{GSA})^{1}$ que se baseou em duas medidas fundamentais: a de estabelecer uma rígida regulação prudencial, que proibia a constituição dos bancos universais; e a formação de uma rede de segurança, que assegurasse os depósitos efetuados nas instituições bancárias e que impedisse ameaças à estabilidade do sistema financeiro.

A economia norte-americana na década de 1920 havia sido tomada por um clima de euforia. O mercado imobiliário apresentava contínua valorização de preço dos terrenos, e o mercado acionário exibia sucessivas apreciações das ações na Bolsa de Valores de Nova York. O movimento destes dois mercados foi favorecido pela falta de regras de regulação financeira e a inexistência de um sistema de crédito agrícola eficiente, que resultaram na formação das primeiras "bolhas" financeiras daquela economia. Houve expressivo aumento no número de fraudes, em operações no mercado imobiliário, relacionado com os preços e até mesmo com a própria existência dos terrenos negociados. Este processo de fraudes teve sua disseminação favorecida pela existência de inúmeros bancos, com características de bancos universais, que estavam autorizados a operar em qualquer segmento do mercado financeiro (Bernanke 2000).

A expansão do crédito bancário e a especulação financeira chegaram a seu limite em 24 de outubro de 1929, com o "crash da bolsa". No setor de crédito, 9.096 bancos quebraram e as cotações das ações perderam $87 \%$ de seu valor de face entre setembro de 1929 e julho de 1932. As atividades econômicas regrediram ao nível de 1913. A supressão dos créditos americanos a outros países, a paralisação das exportações para a América e a queda dos preços das matérias-primas deu amplitude mundial à crise (Galbraith 1997).

O choque na bolsa de valores foi potencialmente maior devido ao efeito "escândalo" causado pelo estado de vulnerabilidade em que o público se viu envolto. Isso implicou aos bancos universais, além das perdas efetivas, o incremento da perda de confiança. Por meio dos canais de transmissão, os bancos de investimento, diretamente atingidos pela crise da bolsa, afetaram os resultados dos bancos comerciais que foram ainda mais prejudicados pela corrida bancária que, pelo efeito contágio, provocou a quebra de diversos bancos. Como os bancos comerciais são os principais provedores de crédito no mercado, a oferta de moeda foi reduzida e a depressão na economia real se sucedeu ao crash financeiro (de Bandt \& Hartmann 2000).

\footnotetext{
${ }^{1}$ A primeira Lei Glass Steagall, editada em 1932, não passou de uma tentativa de expansão de crédito.
} 
O processo de contaminação da economia real, iniciada com a falência de diversos bancos no sistema financeiro, evidenciou a necessidade da regulação do sistema bancário. Para tanto, era necessário prover o sistema com ferramentas capazes de formar "barreiras" que impedissem a transmissão dos efeitos de choques externos para a economia real (Kindleberger 1973). Assim, a regulação do sistema financeiro materializou-se via GSA (1933), que foi baseado em dois pilares: a regulação prudencial e as redes de segurança. A regulação prudencial, com foco na regulação bancária, tinha como principal objetivo criar regras de conduta para os bancos de forma a minimizar os riscos das atividades bancárias. A Securities and Exchange Commission (SEC), como órgão componente da rede de segurança, foi criada em 1934 com a função estatutária de proteger a integridade do mercado de títulos, evitar o sentimento de pânico e o clima de instabilidade percebido no mercado acionário. Coube à SEC estabelecer regras de conduta voltadas para os bancos de investimento, enquanto a regulação bancária foi dirigida aos bancos comerciais.

Destarte, a estratégia comum de regulação dos sistemas financeiros nos países desenvolvidos foi baseada na segmentação dos mercados com objetivo de interromper os canais de contágio e bloquear a propagação de crises. Mais que regulamentar o descasamento entre ativos e passivos dos bancos, a GSA interrompeu o processo de contágio entre bancos de investimento e comerciais, no mercado de títulos, ao instituir a segmentação do mercado. Desta forma, os bancos de investimento passaram a financiar exclusivamente operações de longo prazo, enquanto que as operações de curto prazo ficaram a cargo dos bancos comerciais.

Para garantir a estabilidade do sistema bancário foram criados os seguintes órgãos federais nos EUA: (i) o Federal Reserve Service, a quem coube a função de emprestador de última instância; (ii) o Office of Controller of Currency como o controlador do meio circulante; e (iii) o Federal Deposit Insurance Corporation (FDIC) na função de garantidor dos depósitos à vista nos bancos comerciais. A rede de segurança que foi montada detinha instrumentos capazes de intervir ex ante, quando a instituição se encontrasse ilíquida, porém, solvente; ou ex post, quando o banco estivesse em situação de insolvência. Neste último caso, o FDIC procederia à identificação e ressarcimento dos depósitos a vista, que eram garantidos aos depositantes por um fundo próprio de reserva. ${ }^{2}$

O seguro de depósito proporcionado pelo FDIC é considerado o principal sistema de segurança adotado pelos órgãos de supervisão, que compõem a chamada regulação de proteção (Flannery 1998). Tem sido a medida mais eficaz no sentido de evitar novas corridas bancárias. Contudo, a garantia de reposição aos depositantes, que detenham valor igual ou inferior a US\$250 mil, ${ }^{3}$ em até três dias da decretação de falência do banco, fez com que nem mesmo durante a crise do subprime, houvesse uma corrida dos clientes aos bancos comerciais para sacar seus depósitos.

Como contrapartida à criação do órgão garantidor do governo, o FDIC, o senado norte-americano impôs aos bancos comerciais a formação de um capital regulamentar, constituído com recursos próprios dos donos da instituição,

\footnotetext{
${ }^{2} \mathrm{O}$ senado norte-americano exigiu que um fundo de reserva fosse financiado pelas próprias instituições financeiras, que contribuíram com uma cota proporcional aos depósitos à vista que detinham em seus bancos. Logo, manter registro dos depósitos em seus balanços passou a representar um custo, o custo para cobrir o sistema de regulação.

${ }^{3} \mathrm{~A}$ partir de 2005 este valor é corrigido quinquenalmente pela taxa acumulada de inflação.
} 
como forma de tornar os controladores co-responsáveis na proporção correspondente a este capital, em caso de falência do banco.

De uma forma geral, os sistemas financeiros se mantiveram sem grandes distúrbios até que a partir dos anos 1970 foram atingidos por choques sucessivos. Destacam-se, desta fase, a aceleração da inflação nos EUA; o colapso do sistema de taxas de câmbio fixo de Bretton Woods, entre 1971 e 1973; as crises do petróleo em 1973 e 1979; e a adoção de políticas monetárias contracionistas pela maior parte dos países industrializados. Além disso, a maior liberdade de capitais, em um mundo cada vez mais globalizado, permitiu o surgimento de inovações financeiras. Como consequência, os bancos passaram a securitizar seus créditos como forma de diminuir a exposição ao risco de suas carteiras. Ademais, o sistema bancário inglês adotou maior flexibilidade em suas regras de supervisão o que, por conseguinte, propiciou o surgimento de arbitragem legal.

As regras no sistema inglês permitiam que quaisquer inovações do sistema financeiro fossem praticadas, desde que não estivessem proibidas por lei. De forma diferente, no sistema norte-americano, as inovações financeiras deveriam obter aprovação prévia do regulador para poderem ser praticadas no mercado financeiro. Assim, os bancos comercias norte-americanos começaram a perder mercado para os bancos de investimento e para os bancos estrangeiros que operavam com empresas do país sem serem alcançados pelas exigibilidades do GSA.

A partir de então teve início um processo de "desregulação" do sistema bancário norte-americano iniciado com a publicação do Depository Institutions Desregulation and Monetory Control Act, de 1980, que acabou com a segregação entre bancos comerciais e de investimentos, eliminou as leis de usura e aumentou o valor do seguro para depósitos bancários. ${ }^{4}$ A possibilidade de operar com o valor dos depósitos à vista, sob a garantia da proteção de um órgão governamental contra a perda do depositante, estimulou a assunção de maiores riscos pelas instituições bancárias.

Somente com a publicação do Acordo de Basiléia em 1988 houve a primeira tentativa em nível global de se implantar uma supervisão e controle na indústria bancária. Os princípios contidos nesse acordo objetivaram estabelecer segurança e a solidez ao sistema financeiro mundial por meio da exigência de um capital mínimo regulatório. Este capital deveria suportar perdas eventuais que implicassem prejuízo aos depositantes e reduzir a alavancagem dos bancos e, como consequência, o risco de insolvência que pudesse culminar em risco sistêmico.

O primeiro acordo teve como tema central o risco de crédito, por ser considerado o principal risco à qual as instituições financeiras estariam expostas. Em princípio, o requisito mínimo de capital para fazer frente aos riscos de crédito foi estipulado em $8 \%$ do capital para ativos ponderados pelo risco da instituição financeira (Goodhart 2005). O risco de mercado foi remetido para uma discussão em data posterior e, embora a categoria de risco operacional não tenha sido reconhecida naquele acordo, ficou claro que este e outros tipos de risco estariam cobertos, de forma implícita, pela exigência de capital mínimo.

\footnotetext{
${ }^{4}$ Em 1999, nos EUA, a lenta desmontagem dos controles e limites estabelecidos do GSA chegou a termo com a publicação do Gramm-Leach-Bliley Act.
} 
Com a publicação do "Capital Requirements and Bank Behaviour: The Impact of The Basel Accord" (Basel Committee on Banking Supervision - BCBS 1999), o Comitê de Basiléia indicava a necessidade de um novo acordo. Dentre os problemas que o Acordo de Capital enfrentava, merecem destaque aqueles relacionados à arbitragem de capital para cobertura de títulos securitizados e a exigência crescente de os bancos utilizarem modelos internos para o cálculo do risco de crédito. Em adição, o avanço da globalização dos sistemas financeiros e a modernização das operações do sistema bancário levaram o Comitê a lançar em 2001 a proposta que passou a ser chamada de "Basiléia II" (implementada em junho de 2004).

O Novo Acordo estabelece que os bancos indiquem qual parte de seu capital será disponibilizado para cobertura dos diversos tipos de risco à qual a instituição está sujeita. Está baseado em três pilares mutuamente complementares: (i) o primeiro pilar refere-se aos requisitos mínimos de capital para cobrir riscos de crédito, mercado e operacional; (ii) o segundo pilar está relacionado ao processo de fiscalização bancária. A nova estrutura exige que o banco central de cada país assegure que cada instituição tenha processos internos sólidos para avaliar a adequação de seu capital em uma análise completa de seus riscos e o enquadramento dos modelos utilizados dentro das propostas de Basiléia II; e (iii) o terceiro pilar refere-se à disciplina de mercado por meio da transparência de informações. Estabelece recomendações e requisitos de divulgação em várias áreas, incluindo a forma que a instituição calcula sua adequação de capital e os métodos de avaliação de risco. ${ }^{5}$

De acordo com a literatura, ${ }^{6}$ uma efetiva transparência nas informações divulgadas aos agentes privados torna-se ferramenta eficaz no monitoramento das instituições financeiras. O Comitê de Basiléia, ao estimular a disciplina de mercado, estimula as instituições financeiras a proporcionar aos participantes do mercado condições de produzir mecanismos próprios de acompanhamento e adequação do risco. Ademais, a transparência das informações levadas ao mercado poderá proporcionar a uniformização dos dados contábeis que são publicados, tornando-os mais consistentes e compreensíveis, o que facilitará o estabelecimento de critérios para a tomada de decisões dos participantes de mercado (Goodhart et al. 2004)

Em um ambiente no qual os princípios de Basiléia II encontravam-se em vigor na Europa, desde o ano de 2007, e que acabavam de ser adotados nos EUA, eclodiu a crise do subprime. Conforme publicação do Financial Times (2008), tal crise vinha sendo anunciada e a magnitude do colapso só seria comparável ao que se seguiu à crise de 1929. Um dos principais motivos para a crise se deve ao incremento de liquidez internacional, acarretado pelo rápido crescimento da China e altos preços do petróleo e comodities, aliado à manutenção das baixas taxas de juros pelo Fed. A combinação desses fatores gerou um ambiente no qual: (i) os bancos comerciais davam crédito imobiliário, a juros baixos, para clientes com pouca credibilidade e sem que houvesse nenhuma garantia real de recebimento - títulos de subprime; (ii) os bancos de investimento se apresentaram ávidos para securitizar esses papéis, transformálos em outros produtos financeiros e espalhar esses derivativos pelo mercado; e (iii) as seguradoras, também se aliaram ao processo ao vender outros deri-

\footnotetext{
${ }^{5} \mathrm{O}$ Novo Acordo introduziu providências específicas ligadas a assuntos como securitização, derivativos e investidores institucionais, entre outros.

${ }^{6}$ Vide, por exemplo, Flannery (1998); Deyoung et al. (2001) ; Jagtiani et al. (2002) .
} 
vativos que acreditavam servir como hedge para aqueles investimentos.

Em 1999, o governo norte-americano, incentivado pelas baixas taxas de juros, ampliou o acesso à casa própria para indivíduos de baixa renda (os subprime) por meio da Fannie Mae. O crédito fácil contribuiu para o aumento do número de imóveis em construção. Em 2002, um novo programa de incentivos fiscais do governo, na ordem de US\$ 2,4 bilhões (Nóbrega 2010), garantiu a construção de casas para um público de baixa renda, desta vez alcançando uma categoria de mutuários NINJA (No Income, No Job and no Asset), devido à baixa exigência de documentação comprobatória de renda ou bens. $\mathrm{O}$ aumento no preço dos imóveis possibilitou o surgimento do instrumento da segunda hipoteca que permitiu ao cidadão ter acesso a novos empréstimos lastreados na diferença entre o valor atual do imóvel e o valor de origem. Deve-se salientar que o incentivo à concessão de crédito fomentou a indústria de securitização e o processo de "originação e distribuição" que buscava transferir, de forma integral, os riscos envolvidos nos pacotes securitizados.

O sucesso da estrutura supracitada estaria assegurado no caso de o preço dos imóveis subir sempre. Entretanto, houve um aumento na taxa de inflação norte-americana e o Federal Reserve decidiu promover um aumento na taxa de juros para neutralizá-la. Entre os anos de 2004 e 2006, a taxa de juros sofreu forte incremento e saltou de $1 \%$ para $5,35 \%$ ao ano. ${ }^{7}$ Os contratos de financiamento, estruturados de forma que as amortizações eram negativas nos primeiros anos, tiveram majoradas suas parcelas e o preço dos imóveis começou a perder valor. As hipotecas deixaram de ser pagas e diversos imóveis foram devolvidos acelerando a depreciação e o colapso do sistema hipotecário.

Os primeiros sinais de contágio do sistema foram percebidos quando a New Century Financial, empresa especializada nos empréstimos subprime, pediu concordata, em abril de 2007 (vide Tabela 1 - síntese dos principais eventos que marcaram a crise do subprime). Em setembro do mesmo ano, o efeito conhecido como "corrida bancária" pôde mais uma vez ser observado quando as filas nas agências do banco britânico Northern Rock obrigaram o Banco da Inglaterra a prestar-lhe um socorro de liquidez depois de saques superiores a US\$ 2 bilhões por parte de seus correntistas.

O ano de 2008 começou sob influência dos maus resultados de 2007 e em março de 2008, o Fed se viu obrigado a intermediar o processo de venda do Bear Stearns ao JP Morgan Chase antecipando-se ao efeito que o risco sistêmico ligado a esta falência poderia originar. Em julho de 2008 as autoridades financeiras nos EUA prestaram assistência aos dois gigantes semi-estatais do setor de hipotecas, Fannie Mae e Fredie Mac. Dois meses depois o governo assumiu o controle das duas empresas ao assumir que os níveis de endividamento destas instituições significavam risco sistêmico para a estabilidade econômica. ${ }^{8}$

Contudo, é o mês de setembro de 2008 que pode ser considerado o epicentro da crise. O Lehman Brothers, depois de passar dias em busca de um comprador e sem ter obtido do Fed o mesmo tratamento dado ao Bear Stearns, pediu concordata. Dias depois o Merrill Lynch, um dos principais bancos de investimento norte-americano, foi vendido ao Bank of America para evitar prejuízos maiores. Ainda no mesmo mês, o Fed anunciou um pacote de so-

\footnotetext{
${ }^{7}$ Fonte: http://www.estadao.com.br/economia/not_eco250292,0.htm

${ }^{8}$ Conforme declaração do secretário do Tesouro americano, Sr. Henry Paulson.
} 
corro de US\$ 85 bilhões para tentar evitar a falência da maior seguradora do país, a AIG.

\section{Um indicador de transparência informacional}

Assim como os grandes desastres aéreos, que não podem ser atribuídos a uma única causa, a crise do subprime não está associada a uma única falha. Líderes do G-20 reuniram-se em abril de 2009, em Londres, e apontaram as falhas de regulação e de supervisão dos mercados financeiros como uma das principais causas para a crise dos subprime. ${ }^{11}$ Lacunas na regulação prudencial permitiram o surgimento de um sistema financeiro paralelo, à margem da regulação, formado por fundos de papéis de curto prazo, fundos de hedge, companhias financeiras, seguradoras, veículos de investimento estruturado e negociantes de valor imobiliário - como o Lehman Brothers. Estas instituições se mostravam ávidas por assumir mais riscos em busca de lucro rápido e imediato.

Segundo Franco \& Rosman (2010), a ausência de incentivos para a geração e divulgação de informações sobre a qualidade de ativos de créditos e o reduzido grau de transparência entre os participantes do mercado financeiro são apontados como dois problemas que permitiram o surgimento e a propagação da crise. Além disso, a existência de bancos "grandes demais para quebrar" é apontada como outro fator preponderante para o surgimento de crises. Em 2009, o Grupo dos 30 destacou a importância de se definir quais são as instituições que devem ser submetidas à regulação prudencial por serem consideradas "grandes demais para quebrar". O principal motivo referese à possibilidade de tais instituições gerarem riscos sistêmicos em virtude da vasta interligação que têm com o sistema financeiro.

Bordo (2008) ressalta que a revogação do GSA foi decisiva para que os bancos de investimento dividissem o mercado com os bancos comerciais. O fato dos bancos de investimento não serem regulados permitiu a alavancagem para níveis extremos de risco. Não obstante, o autor mencionado também destaca que a falência do Lehman Brothers e o aprofundamento da crise obrigaram os bancos de investimento a caminhar no sentido inverso ao da segmentação do mercado. Como consequência, o J.P. Morgan e o Goldman Sachs foram transformados em bancos comerciais e passaram a ser regulados pelo Fed e amparados pelo FDIC. ${ }^{12}$

Para a elaboração de um índice capaz de refletir o grau de transparência e de regulação assume-se que a crise foi desencadeada em um ambiente carente de regulação adequada. Destarte, as expectativas dos agentes foram frustradas levando-os à tomada de decisões equivocadas. Também é importante ressaltar que, este estudo considera, por meio da transparência de informações prestadas ao mercado, diversas grandes instituições financeiras com sedes em 25 países (vide Tabela 2 ).

É observado, sob a ótica dos órgãos de regulação e supervisão, a rigidez do sistema de regulação prudencial nesses países levando em conta a disciplina de mercado, e quais bancos disponibilizavam informações relativas ao grau de risco assumido, sem a exigência formal por parte dos órgãos de regulação. Além do critério de transparência das informações, disponibilidade

\footnotetext{
${ }^{11}$ Ver US Department of the Treasury (2009).

${ }^{12}$ Cabe lembrar que o Bear Stern havia sido comprado pelo J.P. Morgan e a Merril Linch foi comprada pelo Bank of America, vide Tabela 1.
} 
Regulação e transparência 31

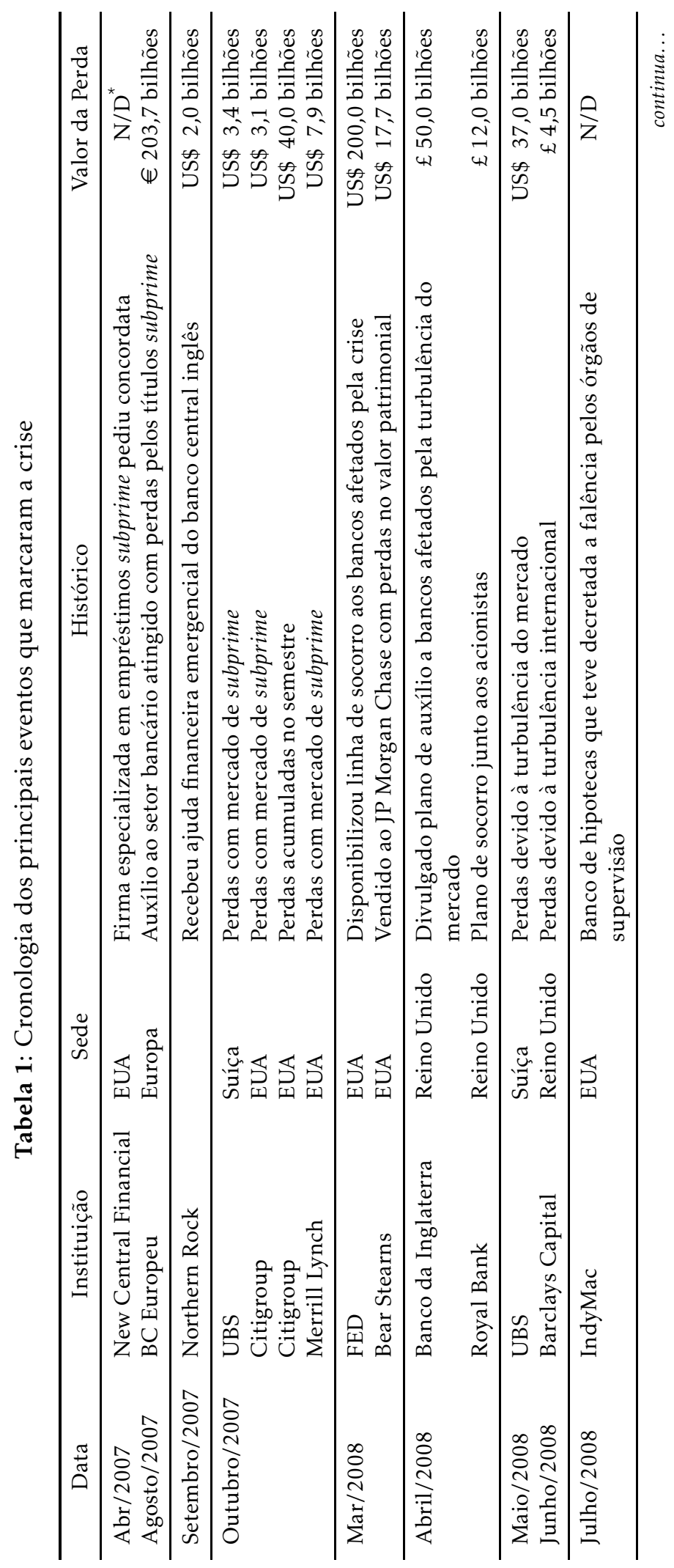




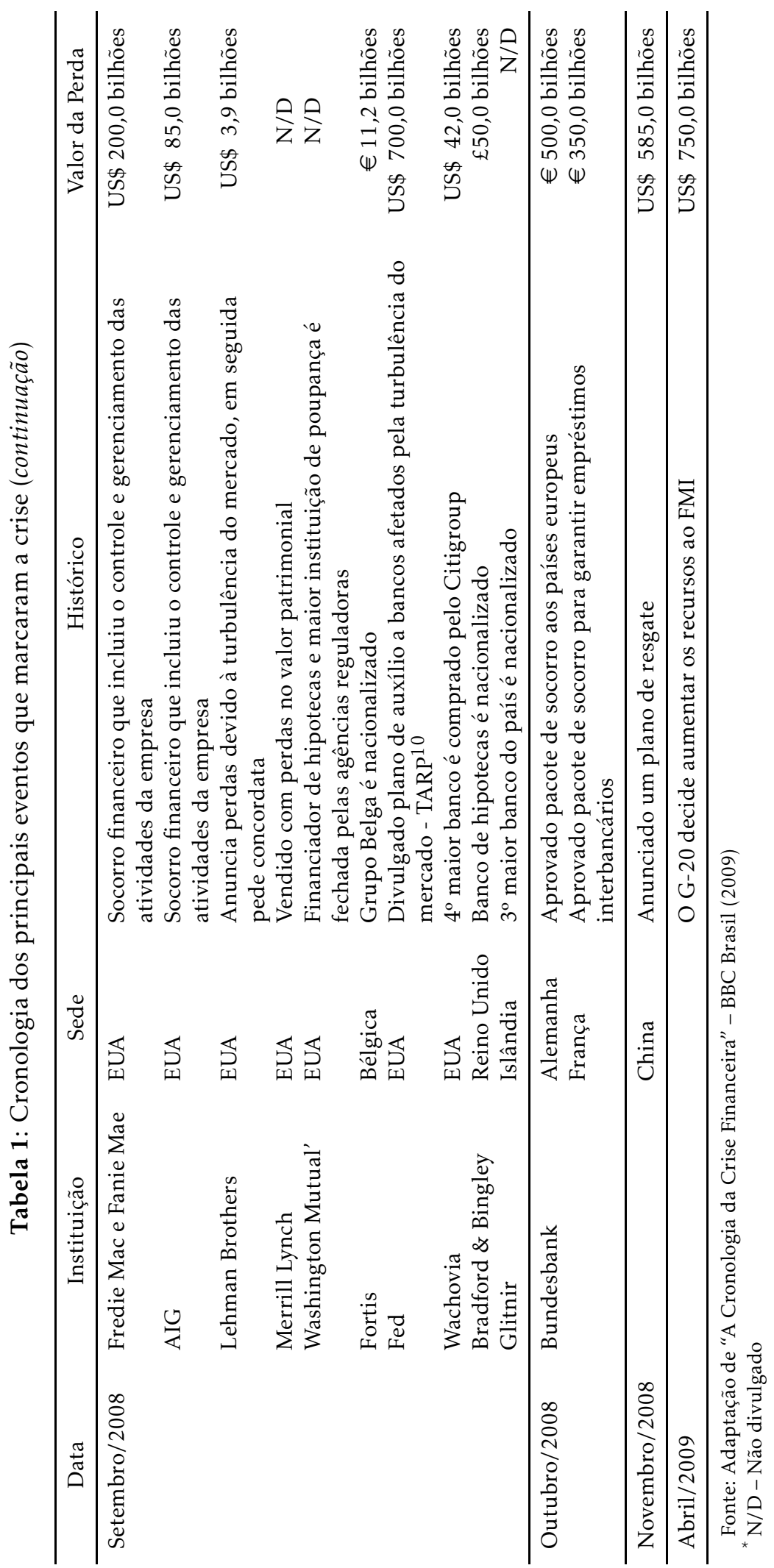


Tabela 2: Relação dos bancos por países na amostra

\begin{tabular}{|c|c|c|c|c|}
\hline N. & País & Órgão de supervisão & Instituição & $\begin{array}{l}\text { Rank } \\
\text { País }\end{array}$ \\
\hline 1 & Alemanha & Deutsche Bundesbank & Dresdner Bank AG & 3 \\
\hline 2 & Austrália & Reserve Bank of Australia & National Australia Bank & 5 \\
\hline 3 & Bélgica & National Bank of Belgium & Fortis Bank & 1 \\
\hline 4 & Canadá & Bank of Canada & Bank of Montreal & 3 \\
\hline 5 & Cingapura & $\begin{array}{l}\text { Monetary Authority of } \\
\text { Singapore }\end{array}$ & $D B S$ & 1 \\
\hline 6 & Espanha & Bank of Spain & Santander & 1 \\
\hline 7 & EUA & Federal Reserve Bank & Citigroup & 1 \\
\hline 8 & França & Bank of France & BNP Paribas & 1 \\
\hline 9 & Grécia & Bank of Greece & EFG Eurobank Ergasias & 3 \\
\hline 10 & Itália & Bank of Italy & Unicredit $S p A$ & 1 \\
\hline 11 & Japão & Bank of Japan & $\begin{array}{l}\text { Mitsubishi UFJ Financial } \\
\text { Group }\end{array}$ & 1 \\
\hline 12 & Nova Zelândia & $\begin{array}{l}\text { Reserve Bank of New } \\
\text { Zealand }\end{array}$ & ANZ National Bank & 1 \\
\hline 13 & Portugal & Bank of Portugal & $B E S$ & 3 \\
\hline \multirow[t]{4}{*}{14} & Reino Unido & Bank of England & $H S B C$ & 3 \\
\hline & & & Barclays Capital & 2 \\
\hline & & & $\begin{array}{l}\text { HBOS - Halifax Bank of } \\
\text { Scotland }\end{array}$ & 4 \\
\hline & & & LLoyds TSB & 5 \\
\hline 15 & Suíça & $\begin{array}{l}\text { The Central Bank of } \\
\text { Switzerland }\end{array}$ & UBS & 1 \\
\hline 16 & Suécia & Sweden & SEB & 2 \\
\hline 17 & África do Sul & South Africa Reserve Bank & Standard Bank & 1 \\
\hline 18 & Argentina & Central Bank of Argentina & La Nacion & 5 \\
\hline \multirow[t]{3}{*}{19} & Brasil & Central Bank of Brazil & Banco do Brasil & 1 \\
\hline & & & Bradesco & 2 \\
\hline & & & Itau & 3 \\
\hline 20 & Chile & Central Bank of Chile & Banco de Chile & 3 \\
\hline 21 & China & The People's Bank of China & Banco da China & 3 \\
\hline 22 & Índia & Reserve Bank of China & State Bank & 1 \\
\hline 23 & México & Bank of Mexico & Banamex & 2 \\
\hline 24 & Rússia & Central Bank of Russia & Sberbank & 1 \\
\hline 25 & Turquia & $\begin{array}{l}\text { Central Bank of Republic of } \\
\text { Turkey }\end{array}$ & Garanti Bank & 4 \\
\hline
\end{tabular}

dos dados em inglês ou espanhol, foram consideradas na amostra instituições/conglomerados que, no âmbito de seus países de origem, são "grandes demais para quebrar" devido ao risco de gerar um risco sistêmico para a economia.

Com base em informações disponibilizadas pelo Banco Mundial e Fundo Monetário Internacional, os países que compuseram a amostra foram classificados em quatro grupos distintos: (i) países desenvolvidos - Alemanha, Austrália, Bélgica, Canadá, Cingapura, Espanha, EUA, França, Finlândia, Grécia, Itália, Japão, Nova Zelândia, Portugal, Reino Unido, Suíça e Suécia; (ii) países que compõem o BRIC: Brasil, Rússia, Índia e China; (iii) países emergentes: África do Sul, China, Índia, Turquia, Rússia, México, Argentina, Brasil e Chile; e (iv) países que compõem o PIGS (Portugal, Itália, Grécia e Espanha). 
Assume-se que a transparência é função da maior ou menor assimetria de informações no âmbito do mercado financeiro. Assim, o aumento de transparência no sistema bancário reduz as incertezas, amplia a capacidade de formação de expectativas, por parte dos agentes econômicos, e cumpre o papel de incentivo a supervisão bancária, por meio da disciplina de mercado. Tomando como referência a literatura sobre transparência do banco central, ${ }^{13}$ a transparência das instituições financeiras pode ser classificada em dois tipos:

A transparência econômica - refere-se à informação financeira (dados, modelos de risco, e previsões financeiras) que é utilizada para a condução da política financeira adotada pela indústria bancária. Duas categorias são consideradas:

A.1 quanto à forma e frequência da divulgação dos índices de riscos das instituições financeiras; e

A.2 quanto à forma e frequência da divulgação das informações contábeis

B transparência política - que pode ser entendida como a transparência institucional - refere-se à acessibilidade do público em relação aos objetivos institucionais e arranjos organizacionais que clarificam a conduta dos responsáveis pela política das instituições financeiras.

O período de análise compreende os meses de setembro, outubro e novembro de 2008 para capturar os efeitos no período mais agudo da crise do subprime. Para a obtenção do "índice de regulação e transparência" (IRT), as respostas foram classificadas com base no seguinte critério (vide tabela 3): (i) o grau 1 foi atribuído às instituições quando a atividade em questão (A1 até B4) é uma exigência feita pelos órgãos de regulação; (ii) o grau 0,5 foi atribuído às instituições quando, apesar de não ser uma exigência dos órgãos de regulação, a instituição bancária executa, de forma regular a atividade em questão; e (iii) o grau 0 (zero) foi atribuído quando a instituição não executa a atividade nem é uma exigência do órgão regulador. ${ }^{14}$

É importante salientar que o requisito de cálculo de capital regulamentar para a cobertura de perdas por risco operacional, inovação introduzida por Basiléia II, também é considerado na análise. Assim, foi feito um levantamento das instituições e bancos centrais que adotaram medidas para implementar o cálculo e divulgação deste risco como forma de avaliar o grau de comprometimento dos agentes econômicos com os princípios de Basiléia II.

A análise dos índices atribuídos aos países do grupo "desenvolvidos" (vide tabela 4) sugere a existência de diferentes estágios de comprometimento com a implantação dos princípios de Basiléia II. Essas diferenças podem ser observadas, por exemplo, ao se comparar as práticas operacionais do Barclays Capital (Reino Unido), que desde 1999 efetua os cálculos do risco operacional utilizando um modelo avançado, contrapondo-se ao banco BES (Portugal) que só recentemente obteve autorização do órgão de supervisão para efetuar o cálculo pelo método padrão. ${ }^{15}$

\footnotetext{
${ }^{13}$ Ver por exemplo, Geraats (2002) e Demertzis \& Hallet (2007).

${ }^{14}$ No caso em que são coletadas informações sobre mais de um banco por país (Reino Unido e Brasil) uma pontuação maior que zero é atribuída quando é observada a característica em ao menos uma das instituições consideradas.

${ }^{15}$ Os métodos de cálculo do risco operacional são: o método do indicador básico, padrão e avançado.
} 
Tabela 3: Estrutura do IRT

\begin{tabular}{|c|c|c|}
\hline Código & Perguntas & Grau \\
\hline$A$ & Transparência Econômica & \\
\hline A.1 & $\begin{array}{l}\text { Relativo aos riscos da instituição e os preceitos de } \\
\text { Basiléia II }\end{array}$ & - \\
\hline A.1.1 & Se a instituição efetua o cálculo do risco de crédito & $0,0.5$ ou 1.0 \\
\hline A.1.2 & $\begin{array}{l}\text { Se é divulgado o risco de crédito em publicações } \\
\text { periódicas }\end{array}$ & $0,0.5$ ou 1.0 \\
\hline A.1.3 & Se a instituição efetua o cálculo do risco de mercado & $0,0.5$ ou 1.0 \\
\hline A.1.4 & $\begin{array}{l}\text { Se é divulgado o risco de mercado em publicações } \\
\text { periódicas }\end{array}$ & $0,0.5$ ou 1.0 \\
\hline A.1.5 & Se a instituição efetua o cálculo do risco operacional & $0,0.5$ ou 1.0 \\
\hline A.1.6 & $\begin{array}{l}\text { Se é divulgado o risco operacional em publicações } \\
\text { periódicas }\end{array}$ & $0,0.5$ ou 1.0 \\
\hline A. 2 & $\begin{array}{l}\text { Relativo às informações contábeis e políticas de } \\
\text { transparência }\end{array}$ & \\
\hline A.2.1 & Se as publicações são disponibilizadas trimestralmente & $0,0.5$ ou 1.0 \\
\hline A.2.2 & Se as publicações são disponibilizadas anualmente & $0,0.5$ ou 1.0 \\
\hline A.2.3 & $\begin{array}{l}\text { Se o índice de Basiléia é calculado e divulgado nessas } \\
\text { publicações }\end{array}$ & $0,0.5$ ou 1.0 \\
\hline$B$ & Transparência Política & \\
\hline B.1 & $\begin{array}{l}\text { Se a estrutura do capital da instituição é divulgada nas } \\
\text { publicações contábeis }\end{array}$ & $0,0.5$ ou 1.0 \\
\hline B. 2 & $\begin{array}{l}\text { Se são divulgados a estrutura e políticas de } \\
\text { administração de riscos }\end{array}$ & $0,0.5$ ou 1.0 \\
\hline B. 3 & Se são divulgadas as políticas de proteção ao risco (hedge) & $0,0.5$ ou 1.0 \\
\hline B.4 & Se são divulgados projeções e cenários do mercado & $0,0.5$ ou 1.0 \\
\hline
\end{tabular}

Outro aspecto identificado diz respeito ao grau de desenvolvimento dos órgãos de supervisão no âmbito da avaliação técnica dos modelos de cálculo mais aprimorados. Segundo o Pilar 2 do Novo Acordo, cabe aos órgãos de supervisão avaliar e aprovar a utilização de modelos de cálculo de risco propostos pelas instituições bancárias. Existe a percepção de que modelos mais aprimorados impliquem menor requerimento de capital econômico o que, por conseguinte, libera recursos da instituição para alavancar suas operações. Com base na amostra selecionada, foram observadas diferenças significativas no estágio de desenvolvimento das análises e autorizações para utilização de modelos próprios de avaliação e cálculo de riscos. Um exemplo, foi o tempo de 18 meses que o Bundesbank, necessitou para autorizar o modelo avançado proposto pelo Dresdner Bank AG (Alemanha), um dos seis bancos alemães já autorizados a fazer uso do método avançado. Por sua vez, na França $60 \%$ dos bancos já estão autorizados a fazer o cálculo do risco operacional baseado em modelos avançados.

As diferenças de estágios em relação à implantação das propostas do Novo Acordo capturados pelo IRT estão refletidos na avaliação final obtida por cada país do grupo "desenvolvidos". Os índices mais elevados (grau 11) são observados para EUA, Nova Zelândia e Suécia. Exceto para o item relativo à publicação do índice da Basiléia (A.2.3), EUA e Nova Zelândia obtiveram grau superior a zero em todos os itens. Embora com a mesma pontuação final, a Suécia obteve uma avaliação maior que zero em todos os quesitos. Por outro 
Tabela 4: Países desenvolvidos

\begin{tabular}{lrrrrrrrrrrrrrr}
\hline I/P & A1 & A2 & A3 & A4 & A5 & A6 & B1 & B2 & B3 & B4 & B5 & B6 & B7 & Total \\
\hline Alemanha & 1,0 & 1,0 & 1,0 & 1,0 & 1,0 & 1,0 & 0,5 & 1,0 & 1,0 & 0,0 & 0,5 & 0,5 & 0,5 & 10,0 \\
Austrália & 1,0 & 1,0 & 1,0 & 0,5 & 1,0 & 0,5 & 0,0 & 1,0 & 1,0 & 0,0 & 1,0 & 1,0 & 0,5 & 9,5 \\
Bélgica & 1,0 & 0,5 & 1,0 & 0,5 & 1,0 & 0,5 & 0,5 & 1,0 & 1,0 & 0,5 & 0,5 & 0,5 & 0,0 & 8,5 \\
Canadá & 1,0 & 1,0 & 0,5 & 0,5 & 1,0 & 0,0 & 1,0 & 1,0 & 1,0 & 0,0 & 0,0 & 0,5 & 0,0 & 7,5 \\
Espanha & 1,0 & 0,5 & 1,0 & 0,5 & 1,0 & 0,5 & 0,5 & 1,0 & 1,0 & 1,0 & 0,5 & 0,5 & 0,5 & 9,5 \\
EUA & 1,0 & 1,0 & 1,0 & 1,0 & 1,0 & 1,0 & 1,0 & 1,0 & 1,0 & 0,0 & 1,0 & 0,5 & 0,5 & 11,0 \\
França & 1,0 & 1,0 & 1,0 & 0,0 & 1,0 & 0,0 & 0,5 & 1,0 & 1,0 & 0,0 & 0,0 & 0,5 & 0,5 & 7,5 \\
Grécia & 1,0 & 0,5 & 1,0 & 0,0 & 1,0 & 0,0 & 0,5 & 1,0 & 1,0 & 0,0 & 0,5 & 0,0 & 0,0 & 6,5 \\
Itália & 1,0 & 0,5 & 1,0 & 0,5 & 1,0 & 0,5 & 0,5 & 1,0 & 1,0 & 0,5 & 0,5 & 0,5 & 0,5 & 9,0 \\
Japão & 1,0 & 0,5 & 1,0 & 0,0 & 1,0 & 0,0 & 0,5 & 1,0 & 1,0 & 0,0 & 0,5 & 0,5 & 0,5 & 7,5 \\
N. Zelândia & 1,0 & 1,0 & 1,0 & 1,0 & 1,0 & 0,5 & 1,0 & 1,0 & 1,0 & 0,0 & 1,0 & 1,0 & 0,5 & 11,0 \\
Portugal & 1,0 & 1,0 & 1,0 & 0,0 & 1,0 & 0,0 & 1,0 & 1,0 & 1,0 & 0,0 & 1,0 & 0,5 & 0,5 & 9,0 \\
Reino Unido & 1,0 & 0,5 & 1,0 & 0,5 & 1,0 & 0,5 & 0,0 & 0,0 & 1,0 & 1,0 & 0,5 & 0,5 & 0,5 & 9,0 \\
Singapura & 1,0 & 1,0 & 1,0 & 0,0 & 0,0 & 0,0 & 1,0 & 1,0 & 1,0 & 0,0 & 0,5 & 0,5 & 0,5 & 7,5 \\
Suécia & 1,0 & 1,0 & 1,0 & 1,0 & 1,0 & 1,0 & 0,5 & 1,0 & 1,0 & 1,0 & 0,5 & 0,5 & 0,5 & 11,0 \\
Suíça & 1,0 & 1,0 & 1,0 & 0,5 & 1,0 & 0,5 & 0,5 & 1,0 & 1,0 & 0,0 & 0,5 & 0,5 & 0,5 & 9,0 \\
\hline
\end{tabular}

lado, o pior desempenho é observado na Grécia $(6,5)$.

Cabe observar que nos EUA, a implementação cara e complexa da Lei Sarbox, que sucedeu aos os escândalos corporativos no ano de $2002,{ }^{16}$ mostrouse insuficiente no sentido de evitar a eclosão da crise em 2008. A Lei Sarbox foi editada com o objetivo principal de aumentar a responsabilidade dos administradores da companhia, das empresas de auditoria e de advogados, por meio da implementação de uma série de regras de governança corporativa. As exigências dessa nova lei, contudo, foram apontadas como uma das causadoras da crise do subprime. Segundo Gottliebsen (2008), por estarem envolvidos demais com aspectos de governança em suas instituições, muitos executivos não puderam perceber as perdas financeiras que alcançavam as operações de suas empresas.

A adesão aos princípios de Basiléia só passou a ser cobrada de forma efetiva nos EUA a partir do início de 2008 e contempla um cronograma de adaptação gradativa de suas regras que se estenderá por mais três anos. Apesar disso, antigas instituições internacionalmente ativas, como o Citigroup, que já haviam aderido à Basiléia II de forma espontânea, alavancaram o índice IRT do país ao grau 11.

A partir das informações coletadas nos sítios de algumas das principais instituições bancárias dos países relacionados na tabela 2, observa-se que há carência de informações relativas às perdas pelos riscos de mercado e operacional, assim como do índice de Basiléia, de forma clara e transparente. Cabe aos órgãos de regulação e supervisão, segundo os princípios de Basiléia, de-

\footnotetext{
${ }^{16}$ A falência da Enron Corporate (Enron), em 2001, quando veio à tona que a empresa teria cometido fraude contábil entre os anos de 1997 e 2001. Ficou comprovado o envolvimento da empresa de consultoria Arthur Andersen S/C, contratada pela Enron, que ajudou a maquiar dívidas transformando-as em parte do patrimônio. A falência do Enron fez levantar a suspeita, nos investidores, de que outras empresas também pudessem estar utilizando-se de "métodos contábeis duvidosos" para melhorar seus resultados. Seguiram-se ao caso Enron os casos da WorldCom em junho de 2001 (considerado o maior caso de falência dos Estados Unidos) e da Xerox que divulgou erros no balanço, dias depois do escândalo da WorldCom. Para mais informações, ver Duarte Jr. \& Varga (2003).
} 
Tabela 5: IRT - Países emergentes

\begin{tabular}{lcccccccccccccc}
\hline I/P & A1 & A2 & A3 & A4 & A5 & A6 & B1 & B2 & B3 & B4 & B5 & B6 & B7 & Soma \\
\hline Argentina & 1,0 & 0,0 & 1,0 & 0,0 & 0,0 & 0,0 & 0,0 & 1,0 & 0,0 & 0,0 & 0,0 & 0,0 & 0,0 & 3,0 \\
África do Sul & 1,0 & 0,5 & 1,0 & 0,5 & 1,0 & 0,5 & 0,0 & 1,0 & 1,0 & 1,0 & 0,5 & 0,5 & 0,0 & 8,5 \\
Brasil & 1,0 & 0,5 & 1,0 & 0,5 & 1,0 & 0,5 & 0,5 & 1,0 & 1,0 & 1,0 & 0,5 & 0,5 & 0,5 & 9,5 \\
Chile & 1,0 & 1,0 & 1,0 & 0,5 & 0,0 & 0,0 & 1,0 & 1,0 & 1,0 & 0,5 & 0,0 & 0,0 & 0,0 & 7,0 \\
China & 1,0 & 1,0 & 1,0 & 0,5 & 1,0 & 0,5 & 1,0 & 1,0 & 1,0 & 0,0 & 0,5 & 0,5 & 0,5 & 9,5 \\
Índia & 1,0 & 0,5 & 1,0 & 0,5 & 1,0 & 0,5 & 0,5 & 1,0 & 1,0 & 0,0 & 0,5 & 0,5 & 0,5 & 8,5 \\
Turquia & 1,0 & 0,5 & 1,0 & 0,5 & 1,0 & 0,0 & 0,5 & 1,0 & 1,0 & 0,0 & 0,5 & 0,5 & 0,0 & 7,5 \\
Rússia & 1,0 & 0,5 & 1,0 & 0,5 & 0,0 & 0,0 & 0,5 & 1,0 & 1,0 & 0,0 & 0,5 & 0,5 & 0,0 & 6,5 \\
México & 1,0 & 1,0 & 0,0 & 0,0 & 1,0 & 0,0 & 1,0 & 1,0 & 1,0 & 0,0 & 0,0 & 0,0 & 0,0 & 6,0 \\
\hline
\end{tabular}

terminar quais, e com que periodicidade, informações contábeis e relativas aos riscos que envolvem as operações da instituição devem ser disponibilizadas, de forma clara e compreensível, a todos os agentes econômicos e não só aos investidores institucionais. Os bancos internacionalmente ativos devem padronizar suas informações, de forma a permitir melhor comparação e avaliação dos riscos pelos agentes de mercado favorecendo, assim, a disciplina do mercado. Se a transparência das informações for de fato ampliada, os agentes de mercado poderão melhorar seus critérios de formação de expectativas e o mercado tenderá a operar em um ambiente menos volátil.

Os países emergentes possuem como característica um crescimento econômico elevado na última década, mas ainda não alcançaram o grau de desenvolvimento econômico necessário para serem classificados como países desenvolvidos. A amostra utilizada neste estudo além de conter os países BRIC (Brasil, Rússia, China e Índia), também considera Argentina, África do Sul, Chile, Turquia, Rússia e México.

De uma forma geral, os BRIC apresentaram um desempenho (medido pelo IRT) superior aos demais países emergentes. Não obstante, além dos BRIC, outro destaque positivo deve ser feito com relação ao IRT alcançado pela África do Sul (8,5 - vide Tabela 5). Este resultado pode ser atribuído à atuação do Standard Bank (maior banco sul-africano) que divulga periodicamente seus índices de exposição ao risco (risco de crédito, operacional e de mercado) em seu balanço anual. Em contrapartida, o pior desempenho entre os 25 países da amostra foi obtido pela Argentina (IRT = 3). A principal razão para esse desempenho se deve a não obrigatoriedade da publicação de índices de avaliação de risco, mas apenas a publicação dos balanços patrimoniais das firmas bancárias. Ademais, a Argentina foi o único país dentre todos os países analisados que não apresentou a publicação da estrutura de capital de suas instituições financeiras (B.1).

O México foi outro país que obteve baixo IRT $(6,0)$, abaixo da média entre os países de seu grupo $(7,0)$. Os bancos mexicanos não calculam e não publicam dados relativos ao risco de mercado (A.1.3 e A.1.4), além de não divulgarem suas políticas de administração e mitigação de riscos, ou de elaborar projeções de cenários para o mercado (B.2, B.3 e B.4). Por fim, Chile e Turquia apresentaram resultados que ficaram na média dos demais países do grupo (7,0 e 7,5 respectivamente), o que pode sugerir a necessidade de regras mais rígidas por parte do órgão regulador desses países.

A análise para as instituições e órgãos de supervisão nos BRIC merece atenção em função destes países virem sendo apontados como as maiores for- 
Tabela 6: IRT - BRIC

\begin{tabular}{lcccccccccccccc}
\hline I/P & A1 & A2 & A3 & A4 & A5 & A6 & B1 & B2 & B3 & B4 & B5 & B6 & B7 & Soma \\
\hline Brasil & 1,0 & 0,5 & 1,0 & 0,5 & 1,0 & 0,5 & 0,5 & 1,0 & 1,0 & 1,0 & 0,5 & 0,5 & 0,5 & 9,5 \\
Rússia & 1,0 & 0,5 & 1,0 & 0,5 & 0,0 & 0,0 & 0,5 & 1,0 & 1,0 & 0,0 & 0,5 & 0,5 & 0,0 & 6,5 \\
Índia & 1,0 & 0,5 & 1,0 & 0,5 & 1,0 & 0,5 & 0,5 & 1,0 & 1,0 & 0,0 & 0,5 & 0,5 & 0,5 & 8,5 \\
China & 1,0 & 1,0 & 1,0 & 0,5 & 1,0 & 0,5 & 1,0 & 1,0 & 1,0 & 0,0 & 0,5 & 0,5 & 0,5 & 10,5 \\
\hline
\end{tabular}

ças futuras da economia mundial antes do ano de 2050. ${ }^{17}$ Brasil e China obtiveram os IRT mais elevados da amostra $(9,5)$. Muito do resultado obtido no caso brasileiro deve-se à divulgação dos relatórios de acompanhamento do sistema bancário, projeções e cenários do mercado (item B.4). Ademais, o Brasil foi o único país dos BRIC que apresentou grau maior que zero para todos os itens (vide Tabela 6).

A entrada de instituições estrangeiras na China somente foi autorizada pelo governo local depois da conclusão de uma ampla reestruturação do sistema bancário doméstico, sobretudo dos quatro grandes bancos públicos: o Banco da China, o Banco da Agricultura da China, o Banco da Construção da China e o Banco Industrial e Comercial da China (BICC). ${ }^{18}$ Outro aspecto relevante na análise do caso da China é que até abril de 2008, apenas dois bancos chineses (o Banco da China e o Banco de Comunicações) possuíam agências bancárias nos EUA, o que reduz sobremaneira sua atuação internacional além da não obrigatoriedade em atender às diversas normas internacionais de regulação prudencial. Não obstante, no momento desta pesquisa, pelo menos seis bancos chineses, entre os quais o BICC, planejavam buscar autorização do Fed para se instalar em território americano. Para tanto, as grandes instituições bancárias chinesas deverão se ajustar aos critérios de regulação prudencial que estiverem vigorando naquele país.

Das instituições bancárias, consideradas nos BRIC, o State Bank, na Índia, foi a que apresentou as melhores condições de visualização das informações requeridas para essa pesquisa. ${ }^{19}$ Os dados estão disponibilizados de forma clara a partir de um link intitulado "Basel II Disclousures", medida que poderia ser adotada como padrão a ser seguido por todas as instituições internacionalmente ativas.

Mais uma vez foi observada distinção significativa entre os índices IRT dos países deste subgrupo. Mínimo de 6,5 atribuído à Rússia e o grau máximo de 9,5 alcançado pelo Brasil e China. Em síntese, a pesquisa feita junto aos sítios dos bancos centrais dos BRIC indicou que o cálculo do capital regulamentar para cobertura dos riscos (crédito, mercado e operacional) era obrigatório e deveria estar disponível para os órgãos de supervisão, contudo, sua divulgação ao mercado, embora incentivada, era uma discricionariedade dos administradores das instituições bancárias. Apenas o Banco Central do Brasil divulga periodicamente o índice de Basiléia das instituições bancárias.

A Rússia é o destaque negativo deste subgrupo tendo alcançado o IRT mais baixo $(6,5)$. Muito deste resultado pode ser atribuído ao fato de os bancos russos não calcularem e não divulgarem o seu risco operacional (A.1.5 e A.1.6),

\footnotetext{
${ }^{17}$ Vide relatório da empresa de consultoria Goldman Sachs (2001).

${ }^{18}$ O BICC é o maior banco do mundo em capitalização de mercado e também o maior dos quatro bancos comerciais estatais da China.

${ }^{19} \mathrm{O}$ State Bank of India é um banco global, com operações em 32 países.
} 
Tabela 7: IRT - PIGS

\begin{tabular}{lcccccccccccccc}
\hline I/P & A1 & A2 & A3 & A4 & A5 & A6 & B1 & B2 & B3 & B4 & B5 & B6 & B7 & Soma \\
\hline Portugal & 1,0 & 1,0 & 1,0 & 0,0 & 1,0 & 0,0 & 1,0 & 1,0 & 1,0 & 0,0 & 1,0 & 0,5 & 0,5 & 9,0 \\
Itália & 1,0 & 0,5 & 1,0 & 0,5 & 1,0 & 0,5 & 0,5 & 1,0 & 1,0 & 0,5 & 0,5 & 0,5 & 0,5 & 9,0 \\
Grécia & 1,0 & 0,5 & 1,0 & 0,0 & 1,0 & 0,0 & 0,5 & 1,0 & 1,0 & 0,0 & 0,5 & 0,0 & 0,0 & 6,5 \\
Espanha & 1,0 & 0,5 & 1,0 & 0,5 & 1,0 & 0,5 & 0,5 & 1,0 & 1,0 & 1,0 & 0,5 & 0,5 & 0,5 & 9,5 \\
\hline
\end{tabular}

além de não terem por regra a divulgação de projeções e cenários ao mercado (B.4).

A opção por fazer uma análise particular para os países PIGS (Portugal, Itália, Grécia e Espanha) deve-se ao fato de que o alto déficit fiscal revelado na Grécia ao final de 2009 ameaçou a rolagem de sua dívida pública e, como consequência, gerou o risco de contágio nos demais países deste subgrupo por apresentarem problemas de mesma natureza. Os demais países possuem desempenho similar à média observada para os países desenvolvidos. O principal motivo para o baixo IRT grego (6,5 - vide Tabela 7) refere-se à falta de publicação dos índices de riscos de mercado e operacional de suas instituições bancárias, aliado ao fato de que tais medidas não são exigidas pelo órgão de supervisão (A.1.4 e A.1.6). Além disso, os bancos gregos não divulgam suas políticas de proteção e projeções de cenários do mercado (B.3 e B.4).

\section{Evidências empíricas}

Com o objetivo de analisar a consequência de uma maior transparência e comprometimento com a regulação bancária, esta seção apresenta evidências empíricas da relação entre o IRT e os efeitos da crise financeira do subprime. Além dos IRTs obtidos para os 25 países da amostra é considerado o mais conhecido índice da bolsa de valores desses países. O emprego dos índices das bolsas de valores é justificado pelo fato dos mesmos responderem com maior velocidade a crises financeiras. O período de análise compreende os meses de setembro e outubro de 2008, e a frequência dos dados é diária. O uso dos meses supracitados se deve ao fato deles representarem o período mais agudo da crise, pois a partir de então diversas medidas para recuperar o crédito foram tomadas pelos principais bancos centrais do mundo.

Os índices das bolsas de valores foram empregados a partir de duas perspectivas: (i) em termos de sua rentabilidade; e (ii) em termos de sua volatilidade. A rentabilidade (RENT) é calculada a partir da divisão entre o preço (pontos) do índice no período $t+n\left(I P_{t+n}\right)$ e o preço do índice no período $t$ $\left(I P_{t}\right)$, isto é,

$$
\text { RENT }=\left(\frac{I P_{t+n}}{I P_{t}}\right)-1
$$

Para a análise referente à volatilidade dos mercados acionários foi considerado o desvio padrão $(D P)$ dos retornos diários dos índices de bolsa de valores,

$$
D P=\left[\left(\frac{I P_{t+1}}{I P_{t}}\right)-1 ;\left(\frac{I P_{t+2}}{I P_{t+1}}\right)-1 ; \ldots ;\left(\frac{I P_{t+n}}{I P_{t+n-1}}\right)-1\right] .
$$

A tabela 8 apresenta o índice empregado no estudo, sua volatilidade e rentabilidade, além do IRT dos países em questão. 
Tabela 8: IRT, rentabilidade e desvio padrão dos índices das

\begin{tabular}{lllrrr}
\hline N $^{\circ}$ & \multicolumn{1}{c}{ País } & \multicolumn{1}{c}{ Indice } & DP & RENT & IRT \\
\hline 1 & África do Sul & JSE & 0,0336 & $-0,2184$ & 8,5 \\
2 & Alemanha & DAX & 0,0382 & $-0,2233$ & 10,0 \\
3 & Argentina & Merval & 0,0508 & $-0,4318$ & 3,0 \\
4 & Austrália & All Ordinaries & 0,0303 & $-0,2341$ & 9,5 \\
5 & Bélgica & Bel - 20 & 0,0413 & $-0,3321$ & 8,5 \\
6 & Brasil & Ibovespa & 0,0592 & $-0,3246$ & 9,5 \\
7 & Canadá & S \& P TSX Composite & 0,0421 & $-0,2659$ & 7,5 \\
8 & Chile & IPSA & 0,0333 & $-0,1334$ & 7,0 \\
9 & China & Shanghai Composite & 0,0324 & $-0,2565$ & 9,5 \\
10 & Espanha & Madri General & 0,0414 & $-0,3197$ & 9,5 \\
11 & EUA & Dow Jones & 0,0408 & $-0,1893$ & 11,0 \\
12 & França & CAC 40 & 0,0427 & $-0,2203$ & 7,5 \\
13 & Grécia & General Share & 0,0395 & $-0,4413$ & 6,5 \\
14 & India & BSE 30 & 0,0403 & $-0,3249$ & 8,5 \\
15 & Itália & Milan MIBTel & 0,0381 & $-0,2572$ & 9,0 \\
16 & Japão & Nikkei 225 & 0,0514 & $-0,3317$ & 7,5 \\
17 & México & IPC & 0,0394 & $-0,2280$ & 6,0 \\
18 & Nova Zelândia & NZSE 50 & 0,0223 & $-0,1599$ & 11,0 \\
19 & Portugal & PSI 20 & 0,0360 & $-0,2626$ & 9,0 \\
20 & Reino Unido & FTSE 100 & 0,0403 & $-0,2187$ & 9,0 \\
21 & Rússia & Moscow Times & 0,0948 & $-0,4884$ & 6,5 \\
22 & Singapura & Straits Times & 0,0363 & $-0,3875$ & 7,5 \\
23 & Suécia & Stockholm General & 0,0361 & $-0,2830$ & 11,0 \\
24 & Suíça & Swiss Market & 0,0384 & $-0,1487$ & 9,0 \\
25 & Turquia & IMKB 100 & 0,0415 & $-0,2946$ & 7,5 \\
\hline & & & &
\end{tabular}

Com o objetivo de dar uma maior robustez ao modelo foram empregadas duas variáveis de controle que são importantes para caracterizar o ambiente econômico no qual as instituições financeiras estão inseridas. A primeira é uma variável dummy $(D I T)$ relativa à adoção ou não do sistema de metas de inflação. A segunda consiste no índice de estabilidade política e não violência $(E P V) .^{20}$

Os diagramas de dispersão na Figura 1 mostram a relação do IRT com a rentabilidade das instituições financeiras e a volatilidade dos mercados acionários. Os resultados indicam a existência de relação negativa para os dois casos $(R E N T$ e DP $) .{ }^{21}$ Em suma, quanto maior a perda apresentada pelo índice das bolsas de valores de um país, menor é o IRT do mesmo (correlação de 0,54 ). De forma análoga, é observado que quanto maior o desvio padrão dos retornos diários, menor é o IRT(correlação de $-0,39$ ).

Dentre os países analisados, os destaques negativos são os casos de Rússia e Argentina. A Rússia, apesar de apresentar um IRT mediano (próximo aos de México e Chile), foi o país que obteve a maior perda $(-48,84 \%)$ e a maior

\footnotetext{
${ }^{20}$ Disponível em Worldwilde Governance Indicators (www.govindicators.org). Além das variáveis mencionadas também foram consideradas no modelo: risco país, qualidade de regulação e efetividade governamental. Entretanto, as mesmas não apresentaram significância.

${ }^{21} \mathrm{~A}$ inclinação positiva da curva de tendência no gráfico referente à relação entre IRT e rentabilidade na Figura 1 se deve ao fato de que estão sendo analisados retornos negativos.
} 
volatilidade $(0,3)$. Como destaque positivo tem-se a Nova Zelândia que apresentou, junto com os EUA e Suécia, o maior IRT, além da menor volatilidade e uma das menores perdas em seu mercado financeiro.
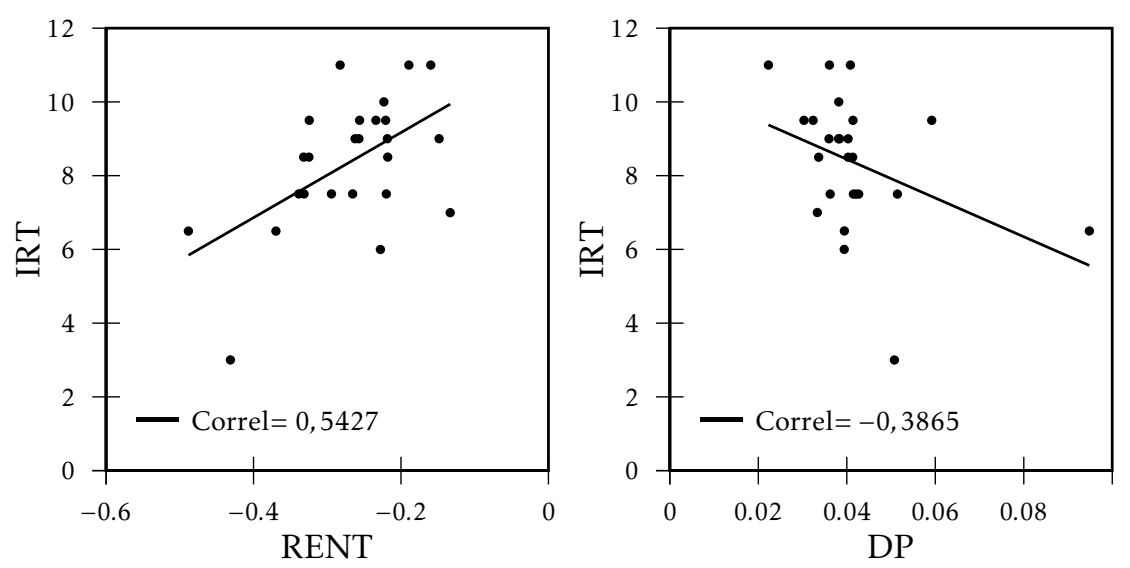

Figura 1: Relação entre IRT e RENT e relação entre IRT e DP

As observações supracitadas sugerem que países com um maior comprometimento com a regulação bancária (elevados IRT) tiveram os efeitos da crise amenizados. De fato, esses mercados registraram menores perdas financeiras e menor volatilidade quando comparado aos resultados dos países cujos IRTs eram mais baixos. ${ }^{22}$ Assim, pode-se inferir que um maior comprometimento das instituições financeiras, em resposta a maior rigidez nas regras impostas pelos órgãos de regulação e supervisão com as regras de transparências propostas pelo Novo Acordo de Basiléia, implicou uma menor exposição nesse período de crise.

Com o objetivo de dar robustez às evidências empíricas encontradas por meio das correlações apresentadas na Figura 1 foram feitas estimações crosscountry (OLS) para avaliar os efeitos da regulação e transparência (IRT) sobre a rentabilidade dos índices das bolsas de valores (RENT) e volatilidade dos mercados acionários $(D P)$. Para facilitar a análise e pelo fato de todos os índices das bolsas de valores analisados apresentarem retornos negativos no período em estudo, a variável RENT foi utilizada em módulo, assim, uma maior "rentabilidade" significa maior perda. Portanto, as equações estimadas, são respectivamente:

$$
\begin{gathered}
|R E N T|=\beta_{0}+\beta_{1} I T R+\beta_{2} D I T+\beta_{3} E P V+\varepsilon, \varepsilon \sim N\left(0, \sigma^{2}\right) . \\
D P=\gamma_{0}+\gamma_{1} I T R+\gamma_{2} D I T+\gamma_{3} E P V+\zeta, \zeta \sim N\left(0, \sigma^{2}\right) .
\end{gathered}
$$

Os resultados encontram-se dispostos na tabela 9. É importante ressaltar que nos três modelos as estatísticas $F$ apresentaram significância estatística e os testes de autocorrelação serial indicaram a não existência da mesma. As

\footnotetext{
${ }^{22}$ Embora o índice de volatilidade do mercado nos EUA não confirme o argumento, a justificativa se deve ao fato dele ter sido o país mais afetado pelas operações praticadas com os "papéis tóxicos"do subprime. Entretanto, a rentabilidade das instituições não foi afetada de forma mais aguda em razão do socorro financeiro prestado pelo Federal Reserve.
} 
Tabela 9: Estimações cross-country (OLS)

\begin{tabular}{|c|c|c|c|c|c|c|}
\hline & \multicolumn{3}{|c|}{$\begin{array}{c}\text { Variável dependente } \\
\text { RENT }\end{array}$} & \multicolumn{3}{|c|}{$\begin{array}{c}\text { Variável dependente } \\
\text { DP }\end{array}$} \\
\hline & Coef. & Stat. & Prob. & Coef. & Stat. & Prob. \\
\hline Constante & 0,461 & 9,000 & 0,000 & 0,061 & 6,654 & 0,000 \\
\hline IRT & $-0,018$ & $-2,728$ & 0,010 & $-0,002$ & $-1,940$ & 0,070 \\
\hline DIT & $-0,068$ & $-3,176$ & 0,000 & $-0,005$ & $-1,223$ & 0,230 \\
\hline EPV & $-0,027$ & $-1,939$ & 0,070 & $-0,006$ & $-1,215$ & 0,240 \\
\hline F-statistic & & 6,684 & 0,002 & & 2,551 & 0,083 \\
\hline Jarque-Bera & & 0,183 & 0,912 & & 49,829 & 0,000 \\
\hline Ramsey Reset (1) & & 3,900 & 0,062 & & 0,451 & 0,510 \\
\hline Ramsey Reset (2) & & 2,025 & 0,160 & & 1,140 & 0,341 \\
\hline Arch LM $(-1)$ & & 0,725 & 0,404 & & 0,225 & 0,640 \\
\hline Arch LM $(-2)$ & & 0,517 & 0,604 & & 0,224 & 0,801 \\
\hline Arch LM (-4) & & 0,390 & 0,813 & & 0,178 & 0,946 \\
\hline Arch LM (-8) & & 0,748 & 0,654 & & 0,126 & 0,996 \\
\hline Breusch-Godfrey LM (-1) & & 0,836 & 0,371 & & 0,128 & 0,725 \\
\hline Breusch-odfrey LM (-2) & & 0,479 & 0,627 & & 0,204 & 0,818 \\
\hline Adjusted $R^{2}$ & & 0,415 & & & 0,162 & \\
\hline$N$ & & 25 & & & 25 & \\
\hline
\end{tabular}

estimações indicam a existência de uma relação negativa da variável dependente com o IRT, o que, por conseguinte, ratifica os resultados obtidos por meio de inspeção gráfica (vide Figura 1). Logo, países com um maior nível de comprometimento, em termos de transparência e regulação bancária, apresentaram perdas menores e menor volatilidade em seus mercados acionários quando comparados com países que possuem um menor comprometimento.

A variável DIT possui coeficiente negativo e apresentou significância estatística nas duas primeiras estimações. Esse resultado indica que países que adotaram metas de inflação apresentaram menores perdas e menor volatilidade em seus mercados financeiros. Ademais, é observado que embora a variável $E P V$ tenha apresentado significância estatística no primeiro modelo, o coeficiente é negativo para os dois casos. Ou seja, é possível conjecturar que países estáveis em termos políticos apresentaram menores perdas em seus mercados.

\section{Considerações Finais}

A crise iniciada nos países desenvolvidos alcançou os países emergentes e há um consenso de que para conter a crise será preciso ações conjuntas dos governos. Contudo, um enrijecimento das regras de regulação prudencial pode ser vista como uma ingerência externa nas operações dos bancos e sistemas financeiros, acostumados com a livre competição e a flexibilidade do mercado. Destarte, a crise pode ter dado fim à tendência de auto-regulamentação do mercado financeiro e de capitais.

As evidências empíricas obtidas neste trabalho chamam a atenção para a importância da regulação e da transparência do setor bancário. Ao se relacionar o IRT com o desempenho do mercado acionário foram encontrados indícios de que ao se reduzir a flexibilização das regras de supervisão, os órgãos de regulação criaram um ambiente que propiciou aos mercados financeiros uma 
maior estabilidade. Em suma, os resultados obtidos reforçam o argumento de que a regulação do sistema financeiro não é neutra em termos macroeconômicos (Blanchard et al. 2010) e que um maior comprometimento por parte da autoridade reguladora pode implicar uma menor vulnerabilidade de seus mercados financeiros.

\section{Referências Bibliográficas}

Basel Committee on Banking Supervision - BCBS (1999), Capital requirements and bank behaviour: The impact of the basel accord, BCBS Working Paper 1, BIS - Bank for International Settlements, Basel.

Bernanke, B. (2000), Essays on the great depression, Technical report, Princeton University Press.

Blanchard, O., Dell'ariccia, G. \& Mauro, P. (2010), Rethinking macroeconomic policy, Technical report, IMF Staff Position Note.

Bordo, M. D. (2008), An historical perspective on the crisis of 2007-2008, Technical report, NBER.

de Bandt, O. \& Hartmann, P. (2000), Systemic risk: A survey, Technical report, European Central Bank.

Demertzis, M. \& Hallet, A. H. (2007), 'Central bank transparency in theory and practice', Journal of Macroeconomics 29 - 4, 760 - 789.

Deyoung, R., Flannery, M. J., Lang, W. W. \& Sorescu, S. M. (2001), 'The information content of bank exam ratings and subordinated debt prices. (statistical data included)', Journal of Money, Credit E Banking 33 - 4, $900-925$.

Duarte Jr., A. M. \& Varga, G. (2003), Gerenciamento de risco em instituições financeiras e o novo acordo de capital, in 'Gestão de riscos no Brasil', Rio de Janeiro, Ed. Financial Consultoria.

Flannery, M. J. (1998), 'Using market information in prudential bank supervision: a review of the u.s. empirical evidence', Journal of Money, Credit $\mathcal{E}$ Banking 30 - 3, 273 - 305.

Franco, G. H. B. \& Rosman, L. A. C. (2010), A crise bancária norte-americana: algumas lições da experiência brasileira, in 'Risco e Regulação', Ed. Campus/Elsevier.

Galbraith (1997), The great crash, Technical report, Boston and New York Mariner Books.

Geraats, P. M. (2002), 'Central bank transparency', Economic Journal 112, 532 -565 .

Goodhart, C. (2005), 'Financial regulation, credit risk and financial stability', National Institute Economic Review 192 - 1, 118 - 127.

Goodhart, C., Hofmann, B. \& Segoviano, M. (2004), 'Bank regulation and macroeconomic fluctuations', Oxford Review of Economic Policy 20 - 4, 591 615. 
Gottliebsen, R. (2008), The curse of sarbanes-oxley, Technical report.

Jagtiani, J., Kaufman, G. \& Lemieux, C. (2002), 'The effect of credit risk on bank and bank holding company bond yields: evidence from the post-fdicia period', Journal of Financial Research 25 - 4, 559 - 575.

Kindleberger, C. P. (1973), The World in Depression 1929-1939, Bekerley: University of California Press.

Nóbrega, M. (2010), Origens da crise, in 'Risco e Regulação', Ed. Campus. 